\title{
Outcomes of bridge to cardiac retransplantation in the contemporary mechanical circulatory support era
}

Joseph E. Sanchez, BS, ${ }^{\text {a }}$ Hiroo Takayama, MD, PhD, ${ }^{\text {a }}$ Masahiko Ando, MD, PhD, ${ }^{a}$ Jiho Han, MD, MS, ${ }^{b}$ Paul Kurlansky, MD, ${ }^{\mathrm{a}}$ Arthur R. Garan, MD, ${ }^{\mathrm{c}}$ Veli K. Topkara, MD, ${ }^{\mathrm{c}}$ Maryjane Farr, MD, Paolo C. Colombo, MD, ${ }^{\mathrm{c}}$ Yoshifumi Naka, $\mathrm{MD},{ }^{\mathrm{a}}$ and Koji Takeda, $\mathrm{MD}, \mathrm{PhD}^{\mathrm{a}}$

\section{ABSTRACT}

Background: Outcomes have improved in patients bridged to heart transplant on contemporary continuous-flow ventricular assist devices over the past decade. We evaluated mechanical circulatory support as a means to bridge patients to cardiac retransplantation.

Methods: We retrospectively reviewed 464 patients who underwent cardiac retransplant from the United Network for Organ Sharing database between January 2006 and November 2016. Pre- and post-transplant data were compared between patients bridged to retransplant with mechanical circulatory support $(n=81)$ and those without mechanical circulatory support $(\mathrm{n}=383)$.

Results: The mean ages for the patients in the mechanical circulatory support and nonmechanical circulatory support cohorts were $41.2 \pm 16$ years and $42.1 \pm 15.7$ years, respectively $(P=.64)$. Patients bridged with mechanical circulatory support were placed on extracorporeal membrane oxygenation $(n=29$, $35.8 \%)$, a total artificial heart $(\mathrm{n}=13,16.0 \%)$, or a temporary or durable ventricular assist device $(n=39,48.1 \%)$. Twelve patients $(14.8 \%)$ were placed on a second device before retransplant. Thirty-nine percent of the mechanical circulatory support group were indicated for listing because of primary graft dysfunction or acute rejection versus $6 \%$ of the nonmechanical circulatory support group $(P<.01)$. Likewise, $30 \%$ of patients in the mechanical circulatory support group were listed for cardiac allograft vasculopathy compared with $59 \%$ of the nonmechanical circulatory support group $(P<.01)$. Thirty-day mortality was significantly higher in the mechanical circulatory support group $(17.8 \%$ vs $4.8 \%$, $P<.01)$. However, patients who were bridged with a ventricular assist device or total artificial heart had comparable midterm outcomes to the nonmechanical circulatory support group.

Conclusions: Patients who require mechanical circulatory support bridge to retransplantation belong to a high-risk cohort. Comparable midterm outcomes to the nonmechanical circulatory support cohort were demonstrated when patients' conditions allow for bridge with a ventricular assist device or total artificial heart. Bridging to retransplantation with extracorporeal membrane oxygenation remains a relative contraindication. (J Thorac Cardiovasc Surg 2019;158:171-81)

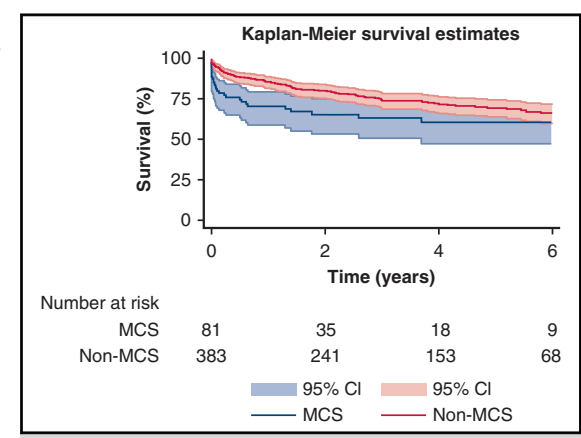

Kaplan-Meier curves for postoperative retransplant survival between the MCS and non-MCS cohorts.

\section{Central Message}

Outcomes have improved in patients bridged to heart transplant with contemporary continuousflow VADs. We analyzed their efficacy in bridging to cardiac retransplantation.

\section{Perspective}

Patients who require MCS bridge to retransplantation belong to a high-risk cohort. However, midterm outcomes comparable to those of the non-MCS cohort were demonstrated when patients' conditions allowed for bridge with a VAD or TAH. Bridging to retransplantation with ECMO remains a relative contraindication.

See Commentaries on pages 182 and 184.
The American Heart Association reports that the United States performs 2600 to 2700 orthotopic heart transplants (OHTs) annually, with an annual trend of plateauing with

From the ${ }^{\mathrm{a} D i v i s i o n}$ of Cardiothoracic Surgery, Department of Surgery, and ${ }^{\mathrm{c}}$ Division of Cardiology, Department of Medicine, New York Presbyterian Hospital, Columbia University Medical Center, New York, NY; and ${ }^{\mathrm{b}}$ Department of Medicine, Stanford University Medical Center, Stanford, Calif.

Read at the 98th Annual Meeting of The American Association for Thoracic Surgery, San Diego, California, April 28-May 1, 2018.

Received for publication May 24, 2018; revisions received Jan 1, 2019; accepted for publication Jan 4, 2019; available ahead of print May 13, 2019. slow increases in prevalence. ${ }^{1}$ However, the graft transplanted can fail acutely or chronically as the result of primary graft dysfunction (PGD), chronic rejection, and

Address for reprints: Koji Takeda, MD, PhD, 177 Ft Washington Ave, New York, NY 10032 (E-mail: kt2485@cumc.columbia.edu). 0022-5223/\$0.00

Published by Elsevier Inc. on behalf of The American Association for Thoracic Surgery

https://doi.org/10.1016/j.jtcvs.2019.01.135 


\section{Abbreviations and Acronyms \\ $\mathrm{CI}=$ confidence interval \\ $\mathrm{d}-\mathrm{VAD}=$ durable ventricular assist device \\ $\mathrm{ECMO}=$ extracorporeal membrane oxygenation \\ $\mathrm{HR}=$ hazard ratio \\ IABP $=$ intra-aortic balloon pump \\ MCS = mechanical circulatory support \\ OHT $=$ orthotopic heart transplant \\ PGD = primary graft dysfunction \\ $\mathrm{TAH}=$ total artificial heart \\ t-VAD $=$ temporary ventricular assist device \\ UNOS $=$ United Network for Organ Sharing \\ $\mathrm{VAD}=$ ventricular assist device}

Scanning this $\mathrm{QR}$ code will take you to the article title page to access supplementary information. To view the AATS Annual Meeting Webcast, see the URL next to the webcast thumbnail.

cardiac allograft vasculopathy. ${ }^{2,3}$ In many of these patients, suggested maintenance treatments include pharmacologic therapy and mechanical circulatory support (MCS) to bridge patients to recovery. ${ }^{3}$ Neither option, though, is viable for long-term maintenance when myocardial recovery is not achieved. In these cases, only retransplantation is sustainable.

Currently, cardiac retransplantation remains a controversial treatment option because of the paucity of organs available and increasing wait-list volumes nationally. Trends in prevalence of cardiac retransplant surgery have fluctuated over the years, plateauing at approximately $1.9 \%$ to $4 \%$ of all cardiac transplants since $1982 .{ }^{4}$ Although little has been reported regarding the characteristics or demographics of those receiving cardiac retransplantations, the operation carries with it one of the highest risks of long-term mortality compared with all other risk factors before surgery. ${ }^{5}$ To improve outcomes, a recent single-center study reported that increasing benefits of MCS can bridge those to cardiac retransplantation with better postoperative long-term outcomes. ${ }^{6}$ With the constant improvement of technology and increasing availability of various MCS, bridge to retransplantation might be an attractive pathway to treat patients with allograft failure. ${ }^{6,7}$ The aim of this study will be to use the United Network for Organ Sharing (UNOS) database to examine the efficacy of contemporary MCS devices in prolonging long-term survival in patients who have received cardiac retransplantation.

\section{MATERIALS AND METHODS}

This study is a retrospective analysis of all patients listed in the UNOS database for a cardiac retransplantation who underwent operation between January 2006 and November $2015(\mathrm{n}=464)$. Those excluded from the study were those who underwent transplantation at less than 18 years of age. The entire cohort was divided into 2 : those who were medically managed before retransplant (non-MCS; $\mathrm{n}=383$ ) and those who received MCS $(n=81)$ to bridge to retransplantation. Intra-aortic balloon pump (IABP) was not considered as MCS in this study. The MCS cohort was then further divided into subgroups based on whether they received extracorporeal membrane oxygenation (ECMO) before retransplant or received another MCS (non-ECMO). Stratification of patients who received multiple devices prioritized ECMO status. Those in the non-ECMO cohort received a temporary ventricular assist device (t-VAD), a durable ventricular assist device (d-VAD), or a total artificial heart (TAH). We analyzed patients on the basis of preoperative characteristics, such as sex, age at the time of listing, listing indication, wait-list time, and time between the primary and secondary transplants. Mortality rates were then compared between the cohorts.

\section{Statistical Analysis}

Statistical analyses were performed using Stata Statistical Software: Release 15.0 (StataCorp LP, College Station, Tex). Categoric variables were analyzed with the Fisher exact test. Normalized, continuous variables were reported as a mean \pm standard deviation and analyzed with a Student $t$ test. Non-normalized, continuous variables were reported as a median (interquartile range) and analyzed with a Mann-Whitney analysis. Mortality was reported as all-cause mortality. Survival analyses were performed using Kaplan-Meier curves and Wilcoxon analyses. Time zero for survival analysis is the event of cardiac retransplantation, with continuous followup thereafter. Censoring occurred only in patients who were lost to follow-up or if the patient was alive at follow-up. Univariable and multivariable Cox regression analyses were performed to assess preoperative risk factors for 30-day mortality and were reported as a hazard ratio (HR) and $95 \%$ confidence interval $(\mathrm{CI})$.

\section{RESULTS}

\section{Baseline Characteristics}

Table 1 demonstrates the comparison of baseline characteristics between groups. Mean age at relisting was similar between the groups. Patients in the MCS group were more likely to be on hemodialysis, IABP, ventilator, and inotropes support. The MCS group was also more likely to have higher total bilirubin and lower cardiac output pretransplantation. In addition, patients in the MCS group were more likely to have undergone a prior cardiac surgery, although the frequency of common procedures was not statistically significant. The indications for listing for cardiac retransplantation were significantly different between the groups. Prevalence of PGD or acute rejection in the MCS group was $39.5 \%$ compared with $6.3 \%$ in the non-MCS group $(P<.01)$. Prevalence of cardiac allograft vasculopathy in the MCS group was $29.6 \%$ and $58.7 \%$ in the nonMCS group $(P<.01)$. Other etiologies for listing were not statistically significant between groups. The MCS group was most commonly listed for 1a status, as was the nonMCS group but at a significant difference in frequency within the patient cohorts $(96.3 \%$ vs $45.7 \%$, respectively, $P<.01)$. The median duration of support for the MCS cohort was 17 days (4-87). Average time on the waitlist 
TABLE 1. Preoperative characteristics of mechanical circulatory support and nonmechanical circulatory support retransplantation cohorts

\begin{tabular}{|c|c|c|c|}
\hline Variables & $\begin{array}{c}\text { MCS } \\
\mathbf{N}=\mathbf{8 1}\end{array}$ & $\begin{array}{c}\text { Non-MCS } \\
\mathbf{N}=\mathbf{3 8 3}\end{array}$ & $P$ value \\
\hline $\begin{array}{l}\text { Age at listing, y } \\
\text { Mean } \pm \text { SD } \\
\text { Median (IQR) }\end{array}$ & $\begin{array}{r}41.2 \pm 15.6 \\
40(25-57)\end{array}$ & $\begin{array}{l}42.1 \pm 15.7 \\
42(28-56)\end{array}$ & .64 \\
\hline Female, n $(\%)$ & $34(40.7)$ & $146(38.1)$ & .42 \\
\hline Height, $\mathrm{cm}$, mean $\pm \mathrm{SD}$ & $170.9 \pm 9.6$ & $171.2 \pm 10.1$ & .82 \\
\hline Weight, $\mathrm{kg}$, mean $\pm \mathrm{SD}$ & $78.1 \pm 18.0$ & $77.7 \pm 16.7$ & .17 \\
\hline BMI, mean \pm SD & $26.7 \pm 5.5$ & $26.4 \pm 4.9$ & .68 \\
\hline $\mathrm{DM}, \mathrm{n}(\%)$ & $14(17.3)$ & $72(18.8)$ & .88 \\
\hline Smoking, n (\%) & $18(22.2)$ & $76(19.8)$ & .65 \\
\hline Hemodialysis, n (\%) & 15 (18.5) & $19(5.0)$ & $<.01$ \\
\hline Creatinine, median (IQR) & $1.5(0.5-2.5)$ & $1.4(0.8-2.0)$ & .36 \\
\hline Total bilirubin (mg/dL), median (IQR) & $1.1(0.7-2.3)$ & $0.7(0.5-1.2)$ & $<.01$ \\
\hline IABP, n (\%) & $10(12.3)$ & $22(5.7)$ & .49 \\
\hline Ventilator, n (\%) & $29(35.8)$ & $5(1.3)$ & $<.01$ \\
\hline Inotropes, n (\%) & $35(43.2)$ & $106(27.7)$ & .01 \\
\hline \multicolumn{4}{|l|}{ Prior cardiac surgery, n (\%) } \\
\hline CABG & $8(9.9)$ & $31(8.1)$ & .66 \\
\hline Valve & $4(4.9)$ & $13(3.4)$ & .51 \\
\hline Valve + congenital & 0 & $5(1.3)$ & - \\
\hline Congenital & $4(4.9)$ & $26(6.8)$ & .80 \\
\hline Other & $26(32.1)$ & $46(12.0)$ & $<.01$ \\
\hline None & $39(48.1)$ & $262(68.4)$ & $<.01$ \\
\hline \multicolumn{4}{|l|}{ Blood type, n (\%) } \\
\hline $\mathrm{O}$ & $36(44.4)$ & $143(37.3)$ & .26 \\
\hline A & $35(43.2)$ & $172(44.9)$ & .81 \\
\hline B & $5(6.2)$ & $52(13.6)$ & .09 \\
\hline $\mathrm{AB}$ & $5(6.2)$ & $16(4.2)$ & .39 \\
\hline Functional status, total assistance & $57(70.4)$ & $117(30.5)$ & $<.01$ \\
\hline $\mathrm{CO}(\mathrm{L} / \mathrm{min})$, mean $\pm \mathrm{SD}$ & $3.8 \pm 1.4$ & $4.4 \pm 1.3$ & $<.01$ \\
\hline MPAP (mm Hg) & $25.1 \pm 8.5$ & $25.5 \pm 8.2$ & .36 \\
\hline MCWP (mm Hg) & $18.5 \pm 7.6$ & $18.3 \pm 7.4$ & .40 \\
\hline PVR (dynes/sec/cm ${ }^{-5}$ ), median (IQR) & $157.1(79.3-218.8)$ & $145.1(84.0-183.3)$ & .22 \\
\hline \multicolumn{4}{|l|}{ Status at reTx, n (\%) } \\
\hline $1 \mathrm{a}$ & $76+2 *(96.3)$ & $175(45.7)$ & $<.01$ \\
\hline $1 \mathrm{~b}$ & $2(2.5)$ & $149(38.9)$ & $<.01$ \\
\hline 2 & $1(1.2)$ & $59(15.4)$ & $<.01$ \\
\hline \multicolumn{4}{|l|}{ ReTx listing indication, n (\%) } \\
\hline Cardiac allograft vasculopathy & $24(29.6)$ & $225(58.7)$ & $<.01$ \\
\hline Chronic rejection & $7(8.6)$ & $46(12.0)$ & .75 \\
\hline PGD or acute rejection & $32(39.5)$ & $24(6.3)$ & $<.01$ \\
\hline Restrictive/constrictive disease & $1(1.2)$ & $16(4.2)$ & .20 \\
\hline Dilated myopathies & $5(6.2)$ & $18(4.7)$ & .58 \\
\hline Other & $12(14.8)$ & $54(14.1)$ & .74 \\
\hline Duration of support, $\mathrm{d}$ & $17(4-87)$ & - & - \\
\hline Waiting list time to re $T \mathrm{x}, \mathrm{d}$, mean $\pm \mathrm{SD}$ & $134.1 \pm 275.1$ & $226.3 \pm 393.3$ & .04 \\
\hline
\end{tabular}


TABLE 1. Continued

\begin{tabular}{|c|c|c|c|}
\hline Variables & $\begin{array}{c}\text { MCS } \\
\mathbf{N}=\mathbf{8 1}\end{array}$ & $\begin{array}{c}\text { Non-MCS } \\
\mathbf{N}=\mathbf{3 8 3}\end{array}$ & $P$ value \\
\hline Time from primary $\mathrm{Tx}$ to reTx, $\mathrm{y}$ & & & $<.01$ \\
\hline Mean \pm SD & $4.7 \pm 5.9$ & $11.2 \pm 6.5$ & \\
\hline Median (range) & $2.0(0.02-7.3)$ & $10.7(5.6-15.9)$ & \\
\hline $\operatorname{ReTx} \leq 3$ mo of primary $\mathrm{Tx}, \mathrm{n}(\%)$ & $27(33.3)$ & $6(1.6)$ & $<.01$ \\
\hline $\operatorname{ReTx} \leq 1$ y of primary reTx, $\mathrm{n}(\%)$ & $30(37.0)$ & $13(3.4)$ & $<.01$ \\
\hline \multicolumn{4}{|l|}{ UNOS region } \\
\hline 1 & $1(1.2)$ & $7(1.8)$ & 1.0 \\
\hline 2 & $14(17.3)$ & $44(11.5)$ & .19 \\
\hline 3 & $10(12.4)$ & $61(15.9)$ & .50 \\
\hline 4 & $11(13.6)$ & $44(11.5)$ & .57 \\
\hline 5 & $9(11.1)$ & $98(25.6)$ & $<.01$ \\
\hline 6 & $2(2.5)$ & $8(2.1)$ & .69 \\
\hline 7 & $6(7.4)$ & $21(5.5)$ & .44 \\
\hline 8 & $5(6.2)$ & $37(9.7)$ & .40 \\
\hline 9 & $11(13.6)$ & $20(5.2)$ & .01 \\
\hline 10 & $8(9.9)$ & $26(6.8)$ & .35 \\
\hline 11 & $4(4.9)$ & $17(4.4)$ & .77 \\
\hline Center volume (cases/10 y) $\dagger$ & Center $n=43$ & Center $n=86$ & \\
\hline Low-volume $(<3)$ & $35(81.4)$ & $41(47.7)$ & $<.01$ \\
\hline Mid-volume (3-5) & $7(16.3)$ & $25(29.1)$ & .13 \\
\hline High-volume $(>5)$ & $1(2.3)$ & $20(23.3)$ & $<.01$ \\
\hline
\end{tabular}

Values in bold represent significant variables for which $P<.05 . M C S$, Mechanical circulatory support; Non- $M C S$, nonmechanical circulatory support; $S D$, standard deviation; $I Q R$, interquartile range; $B M I$, body mass index; $D M$, diabetes mellitus; $I A B P$, intra-aortic balloon pump; $C A B G$, coronary artery bypass grafting; $C O$, cardiac output; $M P A P$, mean pulmonary artery pressure; $M C W P$, mean capillary wedge pressure; $P V R$, peripheral vascular resistance; reTx, retransplantation; $P G D$, primary graft dysfunction; UNOS, United Network of Organ Sharing. *Individuals who never spent a full day listed under a UNOS status classification. $\dagger$ Center volume was calculated between MCS and non-MCS groups using tertiles to separate individual centers' retransplantation cases performed every 10 years. Cutoff values for volume were less than 3 cases (low-volume), 3 to 5 cases (mid-volume), and more than 5 cases (high-volume).

time after relisting was significantly shorter in the MCS group. Likewise, the median time from primary to retransplantation was significantly shorter in the MCS group. Patients in the MCS cohort were more likely than the nonMCS cohort to undergo operation in the UNOS region 9. The retransplantation for the non-MCS cohort was most commonly performed in UNOS region 5 . Region 5 was also statistically more frequently reported in the non-MCS cohort. A greater percentage of low-volume centers received bridged MCS patients than non-MCS patients $(81.4 \%$ vs $47.7 \%, P<.01)$. A greater percentage of highvolume centers received non-MCS patients than those bridged with MCS $(23.3 \%$ vs $2.3 \%, P<.01)$.

\section{Donor Characteristics}

Table 2 describes the preoperative characteristics of the donor group before cardiac retransplantation. Age, sex, body mass index, and preoperative ejection fraction were not significantly different between the groups. In addition, donor-to-recipient weight mismatch and gender mismatch were not different between groups. Among the frequency in causes of death examined, there was no significant difference between the MCS and non-MCS donor cohorts.

\section{Postoperative Outcomes}

Table 3 shows the adverse events after cardiac retransplantation between the MCS and non-MCS cohorts. Median lengths of follow-up between groups were statistically different and longer in the non-MCS cohort (1080 vs 557 days, $P<.01)$. Rates in the causes of death between the groups were not statistically different. Compared with the non-MCS cohort, patients in the MCS group were more likely to require total assistance $(30.9 \%$ vs $14.6 \%$, $P<.01)$ or some assistance $(69.1$ vs $7.6 \%, P<.01)$ posttransplant. All patients in the MCS cohort required some level of functional assistance post-transplant. Patients in the MCS cohort were also more likely to require hemodialysis and have stroke after surgery.

\section{Mechanical Circulatory Support Types}

Table 4 details the specific devices used in the MCS group. ECMO was used in 29 patients $(35.8 \%)$. Others included TAH $(\mathrm{n}=13,16.0 \%)$, t-VADs including left, right, and biventricular support in 25 patients $(30.9 \%)$, and d-VAD in 14 patients $(19.8 \%)$. Nine patients $(10.7 \%)$ were bridged with a second device immediately before retransplant, and 1 patient $(1.9 \%)$ was placed on a third device. 
TABLE 2. Donor preoperative characteristics for mechanical circulatory support and nonmechanical circulatory support cohorts

\begin{tabular}{|c|c|c|c|}
\hline Variables & $\begin{array}{l}\text { MCS, } \\
\mathrm{n}=\mathbf{8 1}\end{array}$ & $\begin{array}{c}\text { Non-MCS, } \\
\mathbf{n}=\mathbf{3 8 3}\end{array}$ & $P$ value \\
\hline Female, n (\%) & $25(30.9)$ & $160(41.8)$ & .08 \\
\hline \multicolumn{4}{|l|}{ Gender mismatch } \\
\hline $\begin{array}{l}\text { Male donor to female } \\
\text { recipient }\end{array}$ & $17(21.0)$ & $51(13.3)$ & .08 \\
\hline $\begin{array}{l}\text { Female donor to male } \\
\text { recipient }\end{array}$ & $9(11.1)$ & $65(17.0)$ & .24 \\
\hline No gender mismatch & $55(67.9)$ & $267(69.7)$ & .79 \\
\hline \multicolumn{4}{|l|}{ Cause of death } \\
\hline Anoxia & $24(29.6)$ & $93(24.3)$ & .33 \\
\hline CVA & $16(19.8)$ & $83(21.7)$ & .77 \\
\hline Trauma & $40(49.4)$ & $196(51.2)$ & .81 \\
\hline CNS tumor & 0 & $2(0.5)$ & - \\
\hline Other & $1(1.2)$ & $9(2.3)$ & .99 \\
\hline BMI $\left(\mathrm{kg} / \mathrm{m}^{2}\right)$, mean $\pm \mathrm{SD}$ & $27.1 \pm 5.4$ & $26.7 \pm 5.7$ & .39 \\
\hline $\begin{array}{l}\text { Ejection fraction }(\%) \\
\text { mean } \pm \mathrm{SD}\end{array}$ & $61.6 \pm 7.7$ & $62.1 \pm 7.6$ & .54 \\
\hline Age & $32.2 \pm 11.6$ & $30.9 \pm 11.9$ & .19 \\
\hline \multicolumn{4}{|l|}{$\begin{array}{l}\text { Donor-to-recipient weight } \\
\text { ratio }\end{array}$} \\
\hline$<0.8$ (undersized), n (\%) & $7(8.6)$ & $50(13.1)$ & .35 \\
\hline $0.8-1.2, \mathrm{n}(\%)$ & $53(65.4)$ & $258(67.4)$ & .79 \\
\hline$>1.2$ (oversized), n (\%) & $21(25.9)$ & 75 (19.6) & .23 \\
\hline $\begin{array}{l}\text { Distance from donor hospital } \\
\text { (miles), median (IQR) }\end{array}$ & $81(13-301)$ & $103(10-306)$ & .48 \\
\hline
\end{tabular}

$M C S$, Mechanical circulatory support; Non-MCS, nonmechanical circulatory support; $C V A$, cerebrovascular accident; $C N S$, central nervous system; $B M I$, body mass index; $S D$, standard deviation; $I Q R$, interquartile range.

\section{Post-Retransplant Survival: Mechanical Circulatory Support Versus Nonmechanical Circulatory Support}

Survival estimates showed a significant difference in the overall all-cause mortality between the non-MCS and the MCS groups $(P<.01)$. Thirty-day survival in the nonMCS group was $95.2 \%$, whereas 30-day survival was $82.2 \%$ in the MCS group $(P<.01)$. For the non-MCS group, 1 - and 5-year survivals were $85.5 \%$ and $69.4 \%$, respectively; for the MCS group, survivals were $70.4 \%$ and $60.5 \%$, respectively (Figure 1).

\section{Post-Retransplant Listing Survival: Mechanical Circulatory Support Versus Nonmechanical Circulatory Support}

Survival estimates showed a significant difference in the overall mortality from time of retransplantation listing between the non-MCS group and the MCS group $(P<.01)$. For the non-MCS group, 1- and 5-year survivals after relisting were $90.4 \%$ and $71.7 \%$, respectively; for the MCS group, survivals after relisting were $72.0 \%$ and $61.1 \%$, respectively.
TABLE 3. Postoperative outcomes for mechanical circulatory support and nonmechanical circulatory support cohorts

\begin{tabular}{lccc}
\hline \multicolumn{1}{c}{ Variables } & $\begin{array}{c}\text { MCS, } \\
\mathbf{n = 8 1}\end{array}$ & $\begin{array}{c}\text { Non-MCS, } \\
\mathbf{n = 3 8 3}\end{array}$ & $\begin{array}{c}\boldsymbol{P} \\
\text { value }\end{array}$ \\
\hline Length of follow-up, d (IQR) & $1080(375-1843)$ & $557(61-1419)$ & $<. \mathbf{0 1}$ \\
Graft failure, n (\%) & $13(16.0)$ & $42(11.0)$ & .19 \\
Functional status & & & \\
$\quad$ Total assistance & $25(30.9)$ & $56(14.6)$ & $<.01$ \\
Some assistance & $56(69.1)$ & $29(7.6)$ & $<.01$ \\
Pacemaker insertion & $1(1.2)$ & $8(2.1)$ & .99 \\
Renal failure and dialysis & $24(29.6)$ & $54(14.1)$ & $<.01$ \\
CVA & $6(7.4)$ & $9(2.3)$ & $\mathbf{. 0 3}$ \\
Cause of death & & & \\
PGD or acute rejection & $5(6.2)$ & $10(2.6)$ & .16 \\
Infection & $5(6.2)$ & $10(2.6)$ & .16 \\
MI & $4(4.9)$ & $15(3.9)$ & .76 \\
CVD & $1(1.2)$ & $7(1.8)$ & .99 \\
PE/ARDS & $1(1.2)$ & $2(0.5)$ & .99 \\
CVA & $1(1.2)$ & $3(0.8)$ & .99 \\
GIB & $1(1.2)$ & $3(0.8)$ & .99 \\
Malignancy & 0 & $5(1.3)$ & - \\
Organ failure & $7(8.6)$ & $16(4.2)$ & .10 \\
Other & $3(3.7)$ & $27(7.0)$ & .33 \\
\hline
\end{tabular}

Values in bold represent significant variables for which $P<.05 . M C S$, Mechanical circulatory support; Non-MCS, nonmechanical circulatory support; $I Q R$, interquartile range; $C V A$, cerebrovascular accident; $P G D$, primary graft dysfunction; $M I$, myocardial infarction; $C V D$, cardiovascular disease; $P E$, pulmonary embolism; $A R D S$, acute respiratory distress syndrome; $G I B$, gastrointestinal bleed.

\section{Comparison Between Extracorporeal Membrane Oxygenation and Nonextracorporeal Membrane Oxygenation Cohorts}

The MCS group was further stratified into those who were bridged to retransplantation with ECMO or nonECMO. Table 5 compares the preoperative characteristics between the 2 groups. The ECMO cohort had a shorter wait-list time compared with the non-ECMO cohort (32.8 vs 190.6 days, $P=.01)$. Indication for listing between the groups was not significantly different, although the ECMO cohort tended to have etiologies related to PGD or acute rejection overall. Kaplan-Meier survival analyses showed significantly worse long-term outcomes in the ECMO group (Figure 2). The 1- and 5-year survivals for the ECMO group were $60.3 \%$ and $49.7 \%$, respectively, and rates for the non-ECMO cohort were $75.8 \%$ and $66.4 \%$, respectively. Kaplan-Meier estimates comparing non-ECMO and non-MCS showed no significant difference in overall survival $(\log -$ rank $=0.349)$.

Within the non-ECMO group, the cohort was further stratified into subtypes consisting of TAH, d-VAD, and $\mathrm{t}$-VAD. The 1- and 5-year survivals were assessed for patients with TAH $(76.9 \%, 65.9 \%)$, t-VAD $(73.8 \%$, $59.6 \%)$, and d-VAD $(78.6 \%, 78.6 \%)$. Overall mortality was not significant between MCS groups (Figure 3). 
TABLE 4. Device types used in patients bridged to cardiac retransplantation

\begin{tabular}{lc}
\hline & MCS used \\
& $\mathbf{N}=\mathbf{8 1}$ \\
\hline ECMO, n (\%) & $29(35.8)$ \\
TAH (SynCardia Cardiowest, Tucson, Ariz), n (\%) & $13(16.0)$ \\
VAD, n (\%) & $39(48.1)$ \\
t-VAD & $25(30.9)$ \\
CentriMag (Abbott, Chicago, Ill) & $14(17.3)$ \\
Impella (Abiomed, Danvers, Mass) & $4(4.9)$ \\
TandemHeart (Cardiac Assist, Pittsburgh, Pa) & $2(2.5)$ \\
Abiomed & $2(2.5)$ \\
Other & $3(3.7)$ \\
d-VAD & $14(19.8)$ \\
HeartMate II (Abbott) & $8(9.9)$ \\
HeartWare HVAD (Framingham, Mass) & $1(1.2)$ \\
Jarvik 200 (New York, NY) & $1(1.2)$ \\
Pulsatile devices & $3(3.7)$ \\
Other (unspecified), n (\%) & $1(1.2)$ \\
\hline
\end{tabular}

$M C S$, Mechanical circulatory support; $E C M O$, extracorporeal membrane oxygenation; $T A H$, total artificial heart; $V A D$, ventricular assist device; $t-V A D$, temporary ventricular assist device; $d$-VAD, durable ventricular assist device.

\section{Outcomes in the Intra-Aortic Balloon Pump Cohort}

There were 22 patients in the non-MCS cohort who had been placed on IABP before transplantation. Initial 30day survival was $95.5 \%$, which was comparable to the non-MCS cohort. One-year survival in this cohort was $76.5 \%$, which was comparable to the VAD or TAH group (Figure E1).

\section{Risk Analysis for Mortality in the Mechanical Circulatory Support Group}

By univariate Cox regression analysis, ECMO was a significant risk factor for 30-day mortality in the MCS group

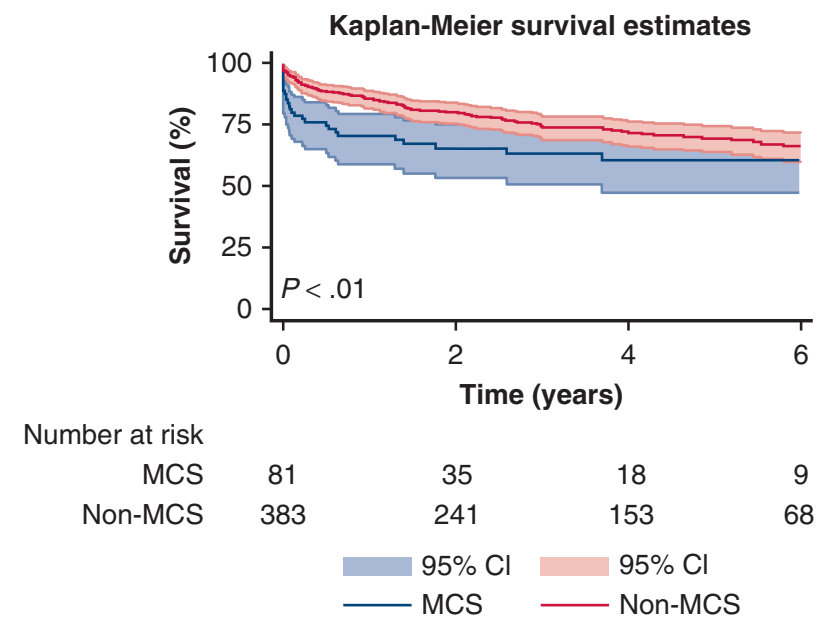

FIGURE 1. Kaplan-Meier curves for long-term survival of postoperative cardiac retransplantation in MCS and non-MCS stratified cohorts. $P$ value generated using Wilcoxon test. MCS, Mechanical circulatory support; Non$M C S$, nonmechanical circulatory support; $C I$, confidence interval.
(HR, 7.07; 95\% CI, 3.39-14.74; $P<.01$ ). Indication of retransplant listing (PGD or acute rejection as reference) was not a significant predictor for 30-day mortality. By multivariable Cox regression analysis, 35 events were noted, and covariate variables analyzed were ECMO, VAD, and age at time of listing. ECMO was found to be a significant risk factor for 30-day mortality in the MCS group (HR, 8.00; 95\% CI, 3.73-17.10; $P<.01)$. VAD use was not a significant risk factor for 30-day mortality in the MCS group (HR, 1.98; $95 \%$ CI, 0.74-5.29; $P=.17$ ). Age at the time of transplant was also not a significant risk factor. Analysis of risk factors for mortality at 1 year did not reach statistical significant for the same variables listed.

\section{DISCUSSION}

Cardiac retransplantation still remains a highly controversial topic with regard to patient outcomes and organ allocation. It has been widely accepted that the decision to direct management toward retransplantation for any patient must be highly dependent on the preoperative assessment of the individual and the expected long-term viable outcomes. Therefore, with the advent of newer models of MCS, the preoperative assessment becomes more complicated when determining how to bridge a patient with the best outcomes. We have corroborated previously accepted conclusions through our analysis of the UNOS database that the ideal patient populations for cardiac retransplant are those who do not require MCS to bridge them to their second transplant, because this group has the lowest rate of short- and long-term mortality. This also includes those who were indicated for relisting under cardiac allograft vasculopathy instead of PGD or acute rejection. In previous years, the patients who needed to be managed with MCS had worse long-term outcomes with more deleterious adverse events compared with those who never required a mechanical device. Khan and colleagues ${ }^{8}$ reported this previously using the UNOS database that compared VAD and ECMO support with medical management in bridging to cardiac retransplantation. They reported poor 1-year outcomes after bridge with VAD (67\%) and ECMO (40\%) compared with their nonbridged group $(71 \%)$. This previous study included devices from 2003 to 2011, and therefore represented outcomes for the previous generation of MCS device models. In comparing their 1-year survival outcomes with our own study, the relative superiority in survival from the support of a newer generation of MCS models suggests possible improvement between eras. This is especially highlighted by the change in 1-year survival rates in patients on ECMO (60.3\% vs $40 \%)$. More recently, Clerkin and colleagues ${ }^{6}$ reviewed cardiac retransplantation with MCS before and after the 2006 UNOS allocation policy change in a single-center study, which proved that strategies involving MCS to bridge to cardiac retransplantation resulted in comparable outcomes to medical management 
TABLE 5. Preoperative characteristics for nonextracorporeal membrane oxygenation and extracorporeal membrane oxygenation mechanical circulatory support cohorts

\begin{tabular}{|c|c|c|c|}
\hline Variables & $\operatorname{Non-ECMO}(n=52)$ & $\operatorname{ECMO}(n=29)$ & $P$ value \\
\hline $\begin{array}{l}\text { Age at listing, } y \\
\text { Mean } \pm \mathrm{SD} \\
\text { Median (IQR) }\end{array}$ & $\begin{array}{l}39.9 \pm 15.7 \\
38(25-57)\end{array}$ & $\begin{array}{l}43.3 \pm 15.5 \\
42(31-58)\end{array}$ & .94 \\
\hline Female, n $(\%)$ & $18(34.6)$ & $15(51.7)$ & .16 \\
\hline Height, $\mathrm{cm}$, mean $\pm \mathrm{SD}$ & $171.7 \pm 10.0$ & $169.6 \pm 9.0$ & .34 \\
\hline Weight, $\mathrm{kg}$, mean $\pm \mathrm{SD}$ & $80.8 \pm 18.1$ & $72.1 \pm 17.0$ & .07 \\
\hline $\mathrm{BMI}$, mean $\pm \mathrm{SD}$ & $27.3 \pm 5.2$ & $24.3 \pm 5.9$ & .16 \\
\hline $\mathrm{DM}, \mathrm{n}(\%)$ & $8(15.4)$ & $6(20.69)$ & .55 \\
\hline Smoking, n (\%) & $14(26.9)$ & $4(13.8)$ & .27 \\
\hline Hemodialysis, $\mathrm{n}(\%)$ & $12(23.1)$ & $3(10.3)$ & .23 \\
\hline Creatinine, median (IQR) & $1.36(0.9-1.8)$ & $1.25(0.9-2.2)$ & .64 \\
\hline Total bilirubin, median (IQR) & $1.0(0.7-1.7)$ & $1.5(0.8-2.7)$ & .09 \\
\hline IABP, n (\%) & $7(13.5)$ & $2(6.9)$ & .48 \\
\hline Ventilator, $\mathrm{n}(\%)$ & $11(21.2)$ & $18(62.1)$ & $<.01$ \\
\hline Inotropes, $\mathrm{n}(\%)$ & $21(40.4)$ & $14(48.3)$ & .64 \\
\hline \multicolumn{4}{|l|}{ Prior cardiac surgery, n (\%) } \\
\hline CABG & $3(5.8)$ & $5(17.2)$ & .13 \\
\hline Valve repair/replaced & $2(3.8)$ & $2(6.9)$ & .61 \\
\hline Congenital & $2(3.8)$ & $1(3.4)$ & .99 \\
\hline Other & $16(30.8)$ & $10(34.5)$ & .81 \\
\hline None & $29(55.8)$ & $11(37.9)$ & .17 \\
\hline \multicolumn{4}{|l|}{ Blood type, n (\%) } \\
\hline $\mathrm{O}$ & $24(46.2)$ & $12(41.4)$ & .82 \\
\hline A & $22(42.3)$ & $13(44.8)$ & .99 \\
\hline $\mathrm{B}$ & $4(7.7)$ & $1(3.5)$ & .65 \\
\hline $\mathrm{AB}$ & $2(3.8)$ & $3(10.3)$ & .34 \\
\hline Functional status, total assistance, $\mathrm{n}(\%)$ & $32(61.5)$ & $25(86.2)$ & .02 \\
\hline $\mathrm{CO}(\mathrm{L} / \mathrm{min})$, mean $\pm \mathrm{SD}$ & $4.2 \pm 1.4$ & $3.1 \pm 1.0$ & .30 \\
\hline $\mathrm{MPAP}(\mathrm{mm} \mathrm{Hg})$, mean $\pm \mathrm{SD}$ & $24.4 \pm 9.3$ & $26.2 \pm 7.0$ & .02 \\
\hline $\mathrm{MCWP}(\mathrm{mm} \mathrm{Hg})$, mean $\pm \mathrm{SD}$ & $18.2 \pm 8.6$ & $19.1 \pm 5.3$ & .40 \\
\hline PVR (dynes $\left./ \mathrm{sec} / \mathrm{cm}^{-5}\right)$, median (IQR) & $115.9(55.1-197.9)$ & $212.3(106.3-249.7)$ & .05 \\
\hline \multicolumn{4}{|l|}{ ReTx listing indication, $\mathrm{n}(\%)$} \\
\hline Cardiac allograft vasculopathy & $19(36.5)$ & $5(17.2)$ & .08 \\
\hline Chronic rejection & $6(11.5)$ & $1(3.4)$ & .41 \\
\hline PGD, acute rejection & $18(34.6)$ & $16(55.2)$ & .10 \\
\hline Restrictive/constrictive disease & $1(1.9)$ & 0 & \\
\hline Dilated myopathies & $3(5.8)$ & $2(6.9)$ & .99 \\
\hline Other & $5(9.6)$ & $5(17.2)$ & .48 \\
\hline Wait-list time to reTx, $\mathrm{d}$, mean $\pm \mathrm{SD}$ & $190.6 \pm 328.1$ & $32.8 \pm 60.3$ & .01 \\
\hline $\begin{array}{l}\text { Time from primary Tx to reTx, y } \\
\text { Mean } \pm \text { SD } \\
\text { Median (range) }\end{array}$ & $\begin{array}{c}4.8 \pm 5.3 \\
2.9(0.3-7.4)\end{array}$ & $\begin{array}{c}4.42 \pm 6.9 \\
0.42(0.01-6.0)\end{array}$ & .78 \\
\hline $\operatorname{ReTx} \leq 3$ mo of primary $\mathrm{Tx}, \mathrm{n}(\%)$ & $13(25.0)$ & $14(48.3)$ & .05 \\
\hline $\operatorname{ReTx} \leq 1$ y of primary $\mathrm{Tx}, \mathrm{n}(\%)$ & $15(28.8)$ & $15(51.7)$ & .06 \\
\hline
\end{tabular}

Values in bold represent significant variables for which $P<.05$. Non-ECMO, Non-extracorporeal membrane oxygenation; $E C M O$, extracorporeal membrane oxygenation; $S D$, standard deviation; $I Q R$, interquartile range; $B M I$, body mass index; $D M$, diabetes mellitus; $I A B P$, intra-aortic balloon pump; $C A B G$, coronary artery bypass grafting; $C O$, cardiac output; $M P A P$, mean pulmonary artery pressure; $M C W P$, mean capillary wedge pressure; $P V R$, peripheral vascular resistance; reTx, retransplantation; $P G D$, primary graft dysfunction; $T x$, transplantation. 


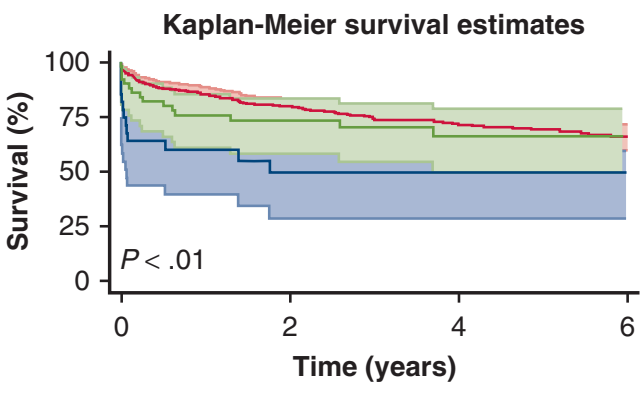

Number at risk

\begin{tabular}{rrccc} 
ECMO & 29 & 8 & 4 & 2 \\
Non-MCS & 383 & 241 & 153 & 68 \\
VAD or TAH & 52 & 27 & 14 & 7 \\
95\% Cl & $95 \% \mathrm{Cl}$ & \multicolumn{2}{c}{$95 \% \mathrm{Cl}$} \\
- ECMO & Non-MCS & \multicolumn{2}{r}{ VAD or TAH }
\end{tabular}

FIGURE 2. Kaplan-Meier curves for long-term survival of postoperative cardiac retransplantation in non-MCS, ECMO, and VAD or TAH stratified cohorts. $P$ value generated using Wilcoxon test. ECMO, Extracorporeal membrane oxygenation; Non-MCS, nonmechanical circulatory support; $V A D$, ventricular assist device; $T A H$, total artificial heart; $C I$, confidence interval.

alone. ${ }^{6}$ We expanded on this study by using the UNOS database for a nationwide report of these outcomes. Our study demonstrated that the overall mortality was lower in the VAD and TAH group when compared with the non-MCS cohort, representing a plausible indication for bridging patients to retransplant in selected patients with VAD or TAH, although definitive conclusions should be made by a further study, including a larger cohort.

Specifically, our initial analysis of the MCS cohort (including VAD, TAH, and ECMO cases) displayed a strong discrepancy between individuals bridged to retransplant with medicine alone or MCS. The MCS group had a significantly higher rate of early mortality than the non-MCS group. This difference in postoperative mortality could be explained by the baseline sickness of the MCS cohort, possibly due to hemodynamic instability requiring MCS, as shown in Table 1. Those in this MCS group also tended to have more complications after retransplantation, although the rates of graft dysfunction postoperatively did not differ significantly. These complications included stroke, impairments in functional status, and renal failure with requirements for dialysis. From this, it is important to recognize that bridging patients to retransplantation with these devices is not without risk. These complications possibly could be explained by the use of MCS in the attempt to bridge a patient to cardiac retransplantation or by the observed baseline difference between the MCS and non-MCS groups, especially with regard to listing indication. Therefore, although we are observing a relative improvement in the all-cause mortality for patients on MCS with newer devices, a different risk profile exists for the patients on MCS bridged to cardiac retransplantation

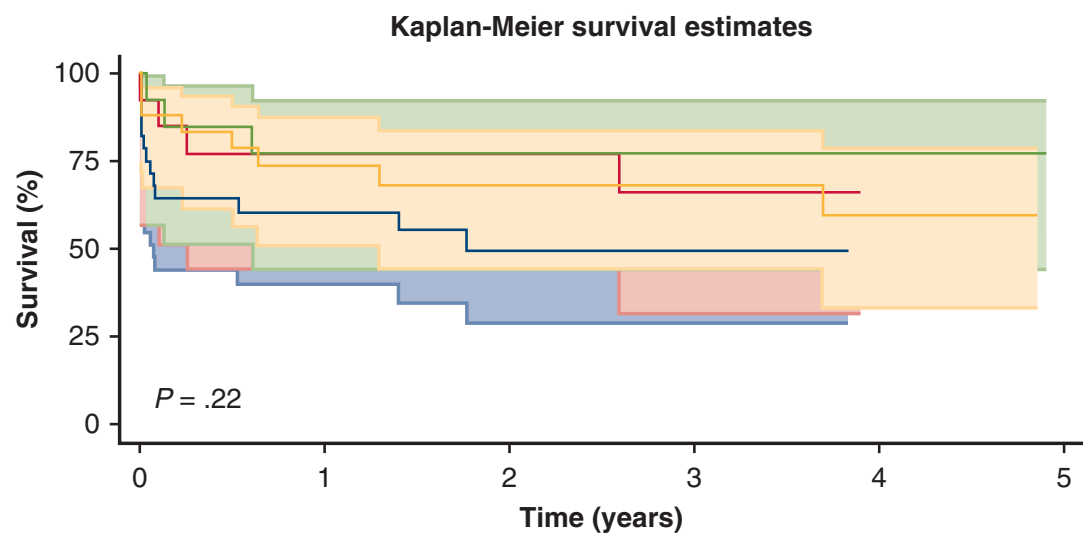

Number at risk

$\begin{array}{rr}\text { ECMO } & 29 \\ \text { TAH } & 13 \\ \text { d-VAD } & 13 \\ \text { t-VAD } & 25\end{array}$

15
9
10
15

8
7
8
12

6
5
7
10

4
3
5
6

4
3
1
5
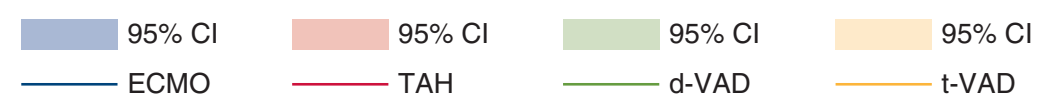

FIGURE 3. Kaplan-Meier curves for long-term survival of postoperative cardiac retransplantation in ECMO, TAH, t-VAD, and d-VAD stratified cohorts. $P$ value generated using Wilcoxon test. ECMO, Extracorporeal membrane oxygenation; $T A H$, total artificial heart; $d$-VAD, durable ventricular assist device; $t-V A D$, temporary ventricular assist device; $C I$, confidence interval. 
that must be addressed. In addition, rates of death from infection in the MCS group were 2 to 3 times higher than in the non-MCS group. Although this did not reach statistical significance, it is important to consider this in the management of these patients postoperatively, because they are prone to device-related infections.

To differentiate underlying factors contributing to the higher mortality within the MCS group, the MCS group was further stratified into subtypes to examine ECMO, TAH, $t-V A D$, or d-VAD. Although the TAH, t-VAD, and d-VAD groups appeared to contribute a similar composite trend in overall survival, no definitive conclusions related to significant differences in survival could be made because of the relatively reduced power in statistically assessing the groups. However, the subgroup analysis did still attribute the worst survival outcomes to the ECMO group. It was determined that non-ECMO MCS mortality was not statistically different than in the non-MCS population; however, the ECMO population had a significant difference in mortality when compared with both groups (Figure 2).

It has been reported that ECMO has been a relative contraindication for cardiac retransplantation. Khan and colleagues $^{8}$ concluded that ECMO after primary transplantation was the greatest negative predictor of overall mortality after cardiac retransplantation. This was later confirmed in 2014 by Belli and colleagues ${ }^{9}$ in a retrospective UNOS study over a 25-year period. Theories put forth for why this discrepancy between ECMO and VAD mortality exists include intrinsic differences in the preoperative characteristics of these patients, because they are sicker and more often experience organ failure. Fukuhara and colleagues ${ }^{10}$ reported that continuous-flow left-heart VAD should be used for bridge-to-bridge support in critically ill patients on ECMO, because early postoperative mortality was significantly higher. As another explanation, VAD placement is often viable in less acute situations that result in fewer postoperative events. These VAD models have improved over the previous decades to allow for longer duration of mechanical support, less pump space required for implantation, and prolonged survival in patient populations. The sole risk factor for early mortality in our study was whether the patient required ECMO to bridge to cardiac retransplantation. Current recommendations for patients on ECMO still include supporting them with other means, such as t-VAD or d-VAD, but not secondary cardiac retransplantation. This is due to the expected early poor mortality and low volumes of organs for allocation. With the upcoming new allocation system, in which ECMOsupported patients receive the highest priority, careful candidate selection for retransplant by each transplant program is of paramount importance.

With our study, we showed that current contemporary models of VADs and TAH in the 2006 to 2016 era have displayed significant improvements in early-term survival after cardiac retransplantation. Therefore, implantation of contemporary MCS could be a viable option for selected patients who require cardiac retransplant. At this time, consideration for cardiac retransplantation in those bridged with ECMO is still not recommended, because primary outcomes of mortality have not improved at a significant rate.

\section{Study Limitations}

Some limitations in this study exist that should be taken into consideration when considering its results. First, the study is retrospective in nature, which limits the power in determining efficacy of these procedures and the impact on clinical decision making. Therefore, we were not able to fully control for the variables assessed in the study, and at times, patient values were omitted from consideration when absent. By extension, the UNOS database is limited to the variables collected that can be retrieved. For instance, specific demographic information, operative variables, and postoperative adverse events were restricted to what was included for the study. In particular, the UNOS database only includes those listed for OHT and fails to report those who are bridged with an MCS device but were not yet listed for transplant. In addition, the UNOS database did not provide for recovery of postoperative complications (ie, stroke, functional status, and renal failure) or the time period when it may have occurred. Therefore, we were unable to assess the recovery of certain patients when comparing MCS and non-MCS groups. Given our limited cohort size and the rarity of retransplantation, conclusions based on the relative superiority and inferiority of devices such as TAH and VADs could not be confidently made. Next, the preoperative characteristics of the MCS and non-MCS cohorts are functionally different in terms of their listing indication. Patients who require MCS are generally sicker, and this is evident by the higher likelihood of an acute indication for cardiac retransplantation. However, this study was unable to fully stratify subgroups of listing indication (ie, PGD vs cardiac allograft vasculopathy) because of poor cohort size and low statistical power. Further, prospective studies would be recommended to review the general outcomes for patients listed for different indications in retransplantation and, specifically, what recommendations can be put forth for patients with varying initial diagnoses.

\section{CONCLUSIONS}

Patients who require mechanical circulatory support bridge to retransplantation belong to a high-risk cohort. Comparable midterm outcomes to the nonmechanical circulatory support cohort were shown when patients' conditions allow for bridge with a ventricular assist device or total artificial heart. Bridging to retransplantation with 
extracorporeal membrane oxygenation remains a relative contraindication.

\section{Webcast \\ You can watch a Webcast of this AATS meeting presenta- tion by going to: https://aats.blob.core.windows.net/ media/18May01/23BC\%203.MCS\%20Transplant/S96_2_ webcast_041905210.mp4.}

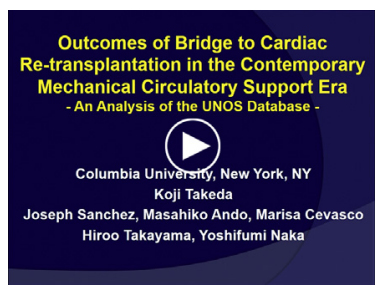

\section{Conflict of Interest Statement}

Associated authors, including Dr Garan, Dr Naka, and Dr Colombo, received grants or funding from the National Institutes of Health, Abiomed, and Abbott. All other authors have nothing to disclose with regard to commercial support.

\section{References}

1. Mozaffarian D, Benjamin E, Go A, Arnett D, Blaha M, Cushman M, et al. Heart disease and stroke statistics_-2016 update: a report from the American Heart Association. Circulation. 2015;133:e38-360.

2. Atluri P, Hiesinger W, Gorman R, Pochettino A, Jessup M, Acker M, et al. Cardiac retransplantation is an efficacious therapy for primary cardiac allograft failure. J Cardiothorac Surg. 2008:3:26.

3. Iribarne A, Hong K, Easterwood R, Yang J, Jeevanandam V, Naka Y, et al. Should heart transplant recipients with early graft failure be considered for retransplantation? Ann Thorac Surg. 2011;92:923-8.

4. Lund L, Edwards L, Kucheryavaya A, Benden C, Christie J, Dipchand A, et al The registry of the International Society for Heart and Lung Transplantation: thirty-first official adult heart transplant report-2014; focus theme: retransplantation. J Heart Lung Transplant. 2014;33:1009-24.

5. Stehlik J, Edwards L, Kucheryavaya A, Benden C, Christie J, Dipchand A, et al The registry of the International Society for Heart and Lung Transplantation: twenty-ninth official adult heart transplant report-2012. J Heart Lung Transplant. 2012;31:1073-86.

6. Clerkin K, Thomas S, Haythe J, Schulze C, Farr M, Takayama H, et al. Mechanical circulatory support as a bridge to cardiac retransplantation: a single center experience. J Heart Lung Transplant. 2015;34:161-6.

7. Yoshioka D, Li B, Takayama H, Garan RA, Topkara VK, Han J, et al. Outcome of heart transplantation after bridge-to-transplant strategy using various mechanical circulatory support devices. Interact Cardiovasc Thorac Surg. 2017;25:918-24.

8. Khan M, Mery C, Zafar F, Adachi I, Heinle J, Cabrera A, et al. Is mechanically bridging patients with a failing cardiac graft to retransplantation an effective therapy? Analysis of the united network organ sharing database. J Heart Lung Transplant. 2012:31:1192-8.

9. Belli E, Moreno J, Hosenpud J, Rawal B, Landolfo K. Preoperative risk factors predict survival following cardiac retransplantation: analysis of the united network for organ sharing database. J Thorac Cardiovasc Surg. 2014;147:1972-7.

10. Fukuhara S, Takeda K, Polanco A, Takayama H, Naka Y. Prolonged continuousflow left ventricular assist device support and posttransplantation outcomes: a new challenge. J Thorac Cardiovasc Surg. 2016;151:881-2.

Key Words: bridge to transplant, mechanical circulatory support, retransplant

\section{Discussion}

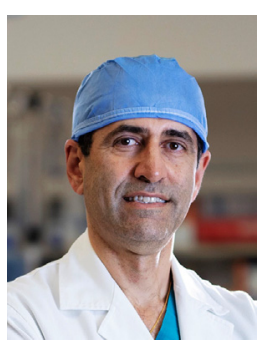

Dr Fardad Esmailian (Los Angeles, Calif). This is an important retrospective study of the UNOS database from 2006 to 2015 that demonstrates survival of the patients bridged to cardiac retransplantation with current contemporary MCS devices has significantly improved compared with previous studies. Furthermore, overall survival for patients requiring ECMO as a bridge to retransplantation continues to be poor, findings that are similar to previous studies with respect to primary cardiac transplantation and is confirmed by the International Society for Heart and Lung Transplantation registry.

I have 4 questions. In the article, you have 10 patients in the MCS group and 14 patients in the non-MCS group who have IABPs. In my opinion, IABP is considered a temporary MCS. Therefore, this group of patients really should be categorized under the MCS group as opposed to 2 separate groups. This might change some of the data and will be a more accurate presentation of the MCS group. I would like to hear your thoughts.

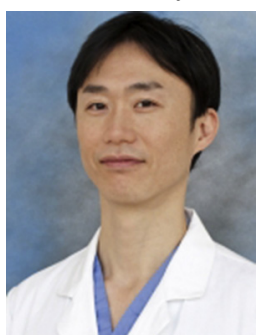

Dr Koji Takeda (New York, NY). This is an issue of the UNOS database. We don't know exactly when the balloon pump was placed. Even if the patient has an MCS, the balloon pump should be removed at the time. There are some patients in the MCS group with concomitant balloon pump, for example, with ECMO and on a balloon pump. These are concomitant. So I don't know if this is data management alone. But in our institution, we don't call a balloon pump an MCS anymore. In each institution, perhaps it is different.

Dr Esmailian. Furthermore, in the article you had $30 \mathrm{pa}-$ tients in the MCS group and 13 patients in the non-MCS group who received retransplants in 1 year or less. In the ECMO group, 15 patients, or 50\% of the ECMO group, received retransplants in 1 year or less of their primary transplant, with 14 of those 15 patients receiving transplants in 3 months or less for a retransplant.

Knowing that the patients who receive retransplants within 1 year of primary transplantation have significantly worse survival, do you think the conclusion about the ECMO could be skewed when you have such a large number of patients with ECMO who receive retransplants in a short time in the database?

Dr Takeda. Generally, patients who require ECMO or who require in the acute phase retransplant are a very sick population, maybe cardiogenic shock status rescued by ECMO. In my opinion, those patients, unless the patient will recover from shock status, perhaps will be extubated 
to contemporary ECMO management; if those were managed ECMO patients, in my mind, the outcome may improve. But in general, this ECMO cohort included patients in shock. If we operate on these patients in shock on ECMO, as you can see, the outcome is not good. So those patients should not receive retransplant.

Dr Esmailian. As a follow-up to that question, there were 15 patients in the ECMO group who received transplant after 1 year of their initial transplant. Do you have the information on that subgroup of patients in terms of their outcome?

Dr Takeda. Actually, no.
Dr Esmailian. I think it will be important to look at those 2 subgroups in the ECMO cohort and try to separate them, because, as you know, the patients receiving transplant at less than 1 year have significantly poor survival. Finally, although the numbers are small, in the article you had 10 patients who were bridged to more than 1 device before retransplantion. Do you know if they are bridged from ECMO to a durable device and then to transplant, and if they were, what were the timing and results?

Dr Takeda. Actually, there are no detailed data. This is a limitation of the UNOS database.

Readers who found these articles interesting may also like to read the following papers found in recent and future issues of our sister publications, Seminars in Thoracic and Cardiovascular Surgery and Operative Techniques in Thoracic and Cardiovascular Surgery!

Adult: Mechanical Circulatory Support

STATE OF THE ART: Interhospital ECMO Transport: Regional Focus. Yaron D. Barac. Semin Thoracic Surg 2019: In press

ORIGINAL SUBMISSION: Surgical Technique for Redo-Sternotomy Sparing Heartware HVAD Exchanges. Thomas Haberl. Oper Tech Thorac Cardiovasc Surg: In press

ORIGINAL SUBMISSION: Novel Cannulation Technique for Temporary Right Ventricular Assist Device After LVAD placement. Leora T. Yarboro. Oper Tech Thorac Cardiovasc Surg: In press

ORIGINAL SUBMISSION: Better With Time: An Economic Assessment of Long-Term Mechanical Circulatory Support in a Population Surviving at Least 1 Year with a Left Ventricular Assist Device. Pavan Atluri. Semin Thoracic Surg 2018: In press

ORIGINAL SUBMISSION: Implantation of the HeartMate 3 -Description of the Surgical Technique. Friedhelm Beyersdorf. Oper Tech Thorac Cardiovasc 2017: 173-185

ORIGINAL SUBMISSION: Greater Omentum Wrapping to Treat Systemic Vad Infections. Sebastian Schulte - Eistrup. Oper Tech Thorac Cardiovasc 2017: 186-197 

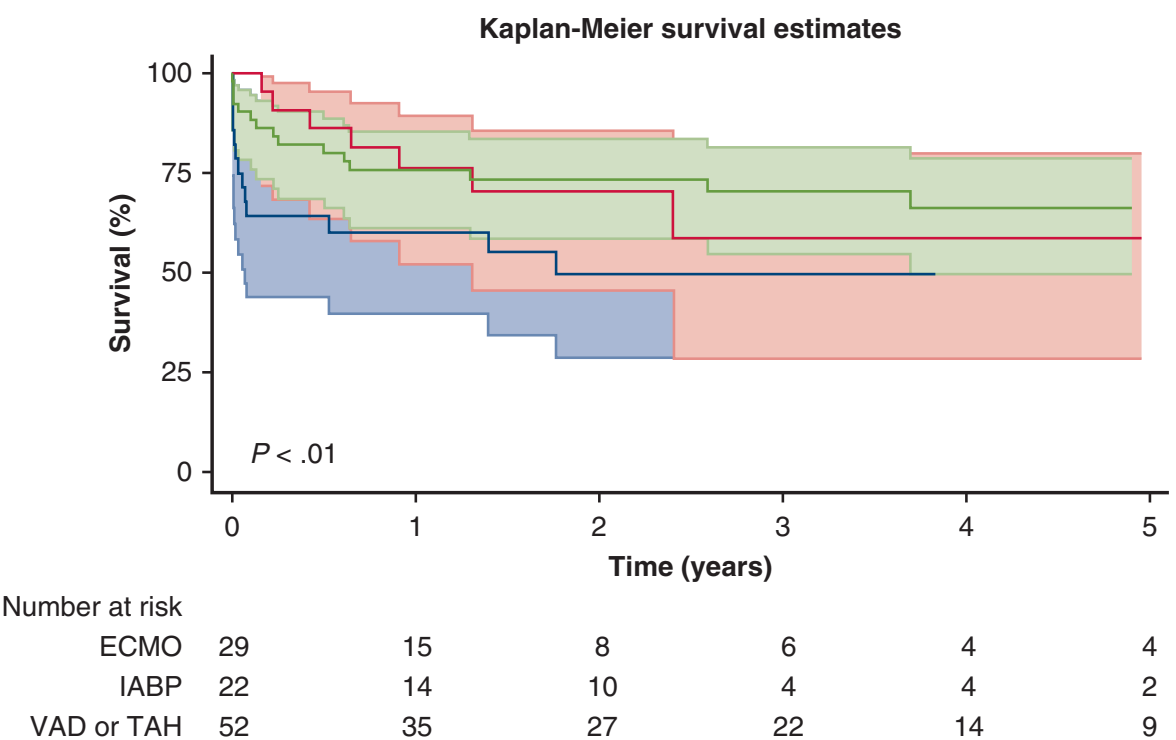

15
14
35
$95 \% \mathrm{Cl}$
ECMO

\begin{tabular}{crr}
8 & & 6 \\
10 & & 4 \\
27 & & 22 \\
& & \\
\multicolumn{3}{c}{$95 \% \mathrm{Cl}$} \\
\multicolumn{3}{c}{ IABP }
\end{tabular}

\begin{tabular}{c}
6 \\
4 \\
22 \\
\hline
\end{tabular}

$\begin{array}{cc}4 & 4 \\ 4 & 2 \\ 14 & 9 \\ & \\ & \\ & \mathrm{Cl}\end{array}$

FIGURE E1. Kaplan-Meier curves for long-term survival of postoperative cardiac retransplantation in ECMO, IABP, and VAD or TAH. $P$ value generated using Wilcoxon test. ECMO, Extracorporeal membrane oxygenation; IABP, intra-aortic balloon pump; VAD, ventricular assist device; TAH, total artificial heart; $C I$, confidence interval. 